\title{
Videoarteterapia. El acto de grabar
}

\author{
Nerea RODRÍGUEZ PÉREZ ${ }^{1}$ \\ Universidad de Vic \\ nereardguez@gmail.com
}

Recibido: $02 / 07 / 13$

Aceptado: $02 / 12 / 13$

\section{RESUMEN}

En este artículo se realiza una introducción al uso del vídeo en las sesiones de arteterapia, reflexionando acerca de la incorporación de la cámara de vídeo como herramienta de creación. Se propone una reflexión teórica a través del proceso de grabación, visualización, edición y análisis posterior de las imágenes centrando el interés en el recorrido de la mirada durante el proceso.

Palabras clave: Videoarteterapia, lenguaje audiovisual, mirada, creación.

\section{Referencia normalizada}

RODRÍGUEZ PÉREZ, N. (2013). "Videoarteterapia. El acto de grabar". En Arteterapia: Papeles de arteterapia y educación artística para la inclusión social Vol.: 8. Páginas 83-103.

\section{SUMARIO}

Introducción. El vídeo en arteterapia: Videoterapia y videoarteterapia. Sobre mi propia experiencia con vídeo en arteterapia. Un trabajo en proceso y multidisciplinar: grabar, editar, visionar, proyectar. La cámara en las sesiones. La materia intangible: Características de la imagen/vídeo y el audio/vídeo. La construcción del universo simbólico en el lenguaje audiovisual: la edición. Análisis formal de la producción. Evolución en la producción: el cambio en la mirada. La mirada. La mirada y el lenguaje audiovisual. La mirada presente en la construcción del universo simbólico. Conclusiones. Referencias bibliográficas.

\section{Videoarttherapy. The act of recording}

\begin{abstract}
This article is an introduction about the utilization of video in arttherapy sessions, considering the video camera as a creation tool. It illustrates the process of filming, editing and analyzing the images, focusing in the gaze evolution along arttherapy sessions.
\end{abstract}

Keywords: Videoarttherapy, audiovisual language, gaze, creation.

\section{CONTENTS}

Introduction. Video in art therapy: video therapy and video art therapy. About my own experience with video in art therapy. A multidisciplinary work in progress: recording, editing, visualizing, projecting. The video camera in art therapy sessions. The intangible assets: image / video and audio / video features. Symbolic universe construction in audiovisual language: the edition. Formal

${ }^{1}$ Licenciada en Bellas Artes (2008) por la Universidad de Vigo, Máster en Artes Visuales y Multimedia (2010) en la UPV y Máster en Arteterapia (2011) por la UVIC. Actualmente realiza su tesis doctoral titulada: "Videoarteterapia. El acto de grabar, editar y evolucionar la producción a través de la mirada. Aplicaciones de su uso en talleres y sesiones de arteterapia supervisadas". 
analysis of production. Evolution in production: the gaze change. The gaze. The gaze and audiovisual language. The gaze presence in the symbolic universe construction. Conclusion. References.

\section{INTRODUCCIÓN}

El vídeo se incorpora a la práctica artística a mediados de los años 60 . Su inicio hay que entenderlo como oposición a la televisión comercial. La cámara de vídeo de la marca Sony se comienza a comercializar durante esa década, por lo que ya no estamos hablando de un útil que solo estaba al alcance de unos pocos sino de un material que pasa a ser de uso común, doméstico.

En relación con el arte, el vídeo se convierte en una herramienta más para disciplinas como la escultura, la música, la danza, el teatro...

El vídeo ofrece, unido al resto de nuevas tecnologías, una nueva materialidad de la obra de arte.

Una nueva forma de entender la manera de acercarse a la producción. E1 tiempo y el espacio, el complemento sonoro y la posibilidad de detenerte ante una pieza, de volver a verla o de intercalar su visionado, abren un amplio abanico de posibilidades renovadas para un medio que se distancia en su dimensión de la escultura, la pintura o la fotografía, y que a su vez bebe de ellas, para generar un nuevo lenguaje, tan válido como los anteriores.

Profundizando en esas nuevas posibilidades que abre el vídeo y estableciendo comparaciones con el resto de lenguajes artísticos destacan características como la temporalidad, la sonoridad o la inmaterialidad del medio ${ }^{2}$ (quizá sea más preciso hablar de "intangibilidad"). La presencia del cuerpo y el contacto de éste con la materia son muy diferentes si lo comparamos con cualquier otro arte. La grabación, la visualización y el editado de las imágenes forman parte del proceso de creación. Durante dicho proceso están presentes diferentes dispositivos que reproducen aquello que se ha producido (la cámara de vídeo, el reproductor y el proyector).

¿En qué punto se genera entonces la implicación? ¿Cómo / cuándo se encuentra el realizante ${ }^{3}$ en contacto con la creación y la materia? ¿Cómo genera impli-

2 Inmaterialidad entendida como la inexistencia de materia tangible como resultado de la producción. La grabación, la imagen vídeo y la edición posterior requieren el uso de aparatos que hacen "físico" lo creado (cámara de vídeo, pantalla de ordenador, televisión, dvd, proyector...).

${ }^{3}$ La Real Academia de la Lengua define "realizar" como: "Efectuar, llevar a cabo algo o ejecutar una acción." y el sufijo "-ante": "que ejecuta la acción expresada por la base". Por tanto el "realizante" es aquel que efectúa, lleva a cabo, ejecuta una acción determinada (en este caso en las sesiones de arteterapia). Palabra creada para alejar a la persona que acude a la sesión del rol de "realizador": "Técnico que va seleccionando una imagen de entre las diversas obtenidas por cámaras situadas en diferentes lugares" o del de "paciente": "Persona que padece física y corporalmente, y especialmente quien se halla bajo atención médica." 
cación un medio que "no es físico", una materia que no tocas, que físicamente no puedes sentir? ¿Dónde / cómo se encuentran las claves para ofrecer una lectura formal de las producciones (o reproducciones) que posibiliten la evolución del trabajo de la persona que acude a una sesión?

A través de mi propia experiencia utilizando la grabación y la imagen vídeo en sesiones de arteterapia he podido observar que lo que posibilita la transformación en el trabajo de vídeo no es tanto la producción en si misma sino la mirada hacia la producción.

Planteo, para su posterior análisis, la hipótesis de que el vídeo, en su uso como medio en arteterapia, encuentra su "materialidad" 4 a lo largo del proceso creativo en el cambio en la mirada del realizante.

El artículo redactado propone, por tanto, un camino en torno al acto de grabar y a su uso como materia de creación en las sesiones de arteterapia

\section{EL VÍDEO EN ARTETERAPIA: VIDEOTERAPIA Y VIDEOARTETERAPIA}

La videoterapia se basa en el uso de los medios audiovisuales con fines terapéuticos. Comienza a resonar con fuerza en los circuitos terapéuticos, ya que todo lo relacionado con las nuevas tecnologías se posiciona a la cabeza de los intereses de los investigadores.

El vídeo no solo se limita a proporcionar una imagen de la realidad, es una escena condicionada por la persona que la graba, la que la edita y la que la observa. Y, por supuesto, de aquello que se está grabando. Por eso tiene tanto interés en el uso terapéutico. Porque permite a la persona trabajar con su propia imagen o con la imagen que tiene del mundo, y ofrece la posibilidad, además, de observar después lo grabado e incluso mostrárselo a los demás. Nos hace extrañarnos ante esa realidad que nos presenta, nos ofrece nuevos puntos de vista de nuestro propio mundo y nos permite elaborar mapas de realidad. Guarda rasgos afines con la fototerapia en su analogía con lo real, aunque el vídeo incorpora el movimiento y ofrece la posibilidad de, además de ver, escuchar.

Susan Sontag señala que el uso de la cámara se asocia a nombrar la realidad y, en cierta medida, a tener control sobre ella ${ }^{5}$. Es por ello que puede ayudar a fortalecer la autoestima, nos obliga a posicionarnos ante la realidad y tomar partido. A su vez, da lugar a la creación de historias, cortometrajes o animaciones, que permitan un trabajo procesual y un posterior análisis.

\footnotetext{
${ }^{4}$ El concepto "materialidad" figura entrecomillado ya que a lo largo del artículo iremos desgranando el significado concreto que se le atribuye desde esta reflexión.

${ }^{5}$ (Sontag, 2008)
} 
La videoterapia tiene dentro de las artes dedicadas a la terapia una consideración diferente. Según Jean Pierre Klein describe en su libro "Arteterapia. Una introducción", la videoterapia no es más que un medio de apoyo por el que poder captar las sesiones y la evolución del paciente mientras desarrolla otro arte concreto: plástica, drama, danza, música; comenta que también es posible hablar de videoterapia cuando se trata de vídeos utilizados por psicoterapeutas que graban sus sesiones y posteriormente trabajan con el visionado de lo que ha ocurrido ${ }^{6}$.

Sin embargo, a partir de los años 70, se comienza a tomar el vídeo no solo como un apoyo para captar lo que ocurre en las sesiones sino que se comienza a hablar de videoarteterapia.

En la videoarteterapia se trabaja con la grabación como un medio para realizar un proceso de creación, es un arte que brinda gran cantidad de posibilidades para el terapeuta a la hora de hacer propuestas, enriquece la obra ya que permite la combinación con cualquier expresión artística y ofrece grandes alternativas y riqueza expresiva para la persona que acude a las sesiones. Es sin embargo un medio artístico con poca repercusión en las formaciones arterapéuticas (comienza a estar muy presente en publicaciones) y no existen gran número de profesionales que la hayan estudiado en profundidad o que pongan en práctica sus múltiples posibilidades.

En EEUU los arteterapeutas Shaun A. Mcniff Y Christopher C. Cook trabajan entre 1973 y 1975 en una investigación sobre el rol que puede jugar el vídeo en arteterapia. Lo llevan a cabo con diferentes grupos de pacientes y si bien en un comienzo el equipo de grabación es incorporado simplemente para tomar imágenes del proceso arteterapéutico, pero no para su uso con estos fines, la aparición de la cámara se vuelve determinante ya que se convierte en la motivadora del proceso grupal. Se fomenta por tanto la creatividad a través de lo que llaman la "Videocreación + videoconfrontación", aunque el vídeo sigue siendo utilizado para documentar otra experiencia arteterapéutica (en este caso a través de la plástica) es importante destacarlo ya que desde ese momento comienza a desempeñar un nuevo papel dentro del trabajo en las sesiones. Conceptos como el videofeedback llegan de la mano de Helveil en torno a 1984 mientras Chin ya trabajaba en torno al concepto de videoterapia. En Inglaterra J. Shaw y C. Robertson nos acercan al concepto de vídeo participativo.

Otros autores que han realizado intervenciones en videoterapia y videoarteterapia: "Berger (1978), Dowrick y Biggs (1983), Fryrear y Fleshman (1981), Hinz y Ragsdell (1990), D.R. Henley (1992), J. Crossfield (2005), Ana Mampaso (2005), Bárbara Mosinsky (2007) "’.

En la actualidad en España se han llevado a cabo investigaciones que relacionan las nuevas tecnologías con el trabajo en arteterapia. Ana Mampaso es Docto-

\footnotetext{
${ }^{6}$ (Klein, 2006, p 28.)

${ }^{7}$ (López Martínez, 2009, p. 284)
} 
ra en Ciencias de la Información por la Universidad Complutense de Madrid, es también cofundadora de la asociación AVERTE (Asociación de Videoterapia Española y Recursos Telemáticos) con O. Rueda, I. Pérez y M. Morales. La tesis doctoral de Ana Mampaso, publicada en el año 2004, lleva por título: "La videoanimación: aplicaciones en los campos del desarrollo social y comunitario, la educación artística y el arte terapia”, en ella toma el vídeo como un medio alternativo de comunicación y enseñanza, profundizando en los terrenos de la educación y el arteterapia.

Trece años antes, en 1991, había publicado Ignacio Rivero Urdiain la tesis doctoral "Aplicaciones del sistema vídeo en psicología clínica: un modelo de investigación y videoterapia", en la que aporta una novedosa perspectiva para la España de entonces del uso clínico del vídeo.

Son muchos los que comienzan a escribir $\mathrm{y}$, sobre todo, a poner en práctica acciones terapéuticas basándose en el vídeo.

Desde el Inecat (Institut National d'Expression, de Creation, d'Art et Transformation) en París se realiza una publicación centrada en el universo del arteterapia, existen algunos números de la revista "Art \& Thérapie" vinculados con la temática de la fotografía y el vídeo ${ }^{8}$.

En Madrid se encuentra la Asociación "Debajo del Sombrero" desde donde se trabaja para la integración de las personas con discapacidad intelectual al mundo de la creación contemporánea. Surge en colaboración con Matadero Madrid (Centro de Creación Contemporánea) la propuesta "Al matadero sin miedo". En ella jóvenes y adultos con discapacidad son invitados a un espacio de creación a través del cual se realizan diferentes proyectos. El que tiene mayor vinculación con el medio audiovisual es el que brinda a su realizador una cámara situada en su cabeza (al tratarse de una persona que no puede controlar ni manos ni piernas) y con ella recorre las calles de Madrid realizando entrevistas relacionadas con la accesibilidad de la ciudad a los transeúntes.

Cinesín, según la describen desde su página web, es una:

Asociación sin ánimo de lucro creada en Valencia en el año 2008 (...). Pretendemos trabajar la accesibilidad de los medios audiovisuales para personas con Diversidad Funcional (término acuñado por el Foro de Vida Independiente). Cinesín propone la Videodiversidad Funcional (VDF) como medio de llegar al pleno acceso a las nuevas tecnologías y medios de comunicación?

Tanto Discapacidad TV, de Barcelona, como Radio Nikosia (desde Barcelona, siguiendo la estela de Radio Colifata), trabajan acercando los medios audiovisuales a personas con discapacidad, aunque de manera muy diferente. Desde Disca-

\footnotetext{
${ }^{8}$ Títulos de interés sobre la temática audiovisual: " $52 / 53$. Photographier, rendre visible le regard.", "74/75. Noir et blanc (tome 1). Peinture et Arts Visuels.", "76/77. Noir et blanc (tome 2)Photo, Psy, Ethnoécriture."

${ }^{9} \mathrm{http}: / /$ www.cinesin.net/quienes.htm [09/12/2013]
} 
pacidadTV se pretende ofrecer un contenido dirigido a la población discapacitada, sin que sea dicha población la que necesariamente decida o lleve a cabo la programación. Radio Nicosia, por el contrario, es una de las primeras emisoras en la que los contenidos se deciden y son realizados por personas que han sido diagnosticadas de problemas de salud mental.

Hemos podido observar que existen muchas experiencias distintas que tratan de aproximarse al vídeo y a su relación con distintos colectivos. Habla Ana Mampaso en su artículo "Vídeo-arte y educación" de las posibilidades que ofrece la cámara de vídeo:

De esta manera el vídeo se revela como un medio muy accesible también para ser utilizado como soporte de la expresión artística: posee ciertas características que lo hacen accesible a cualquier usuario profano, como la facilidad de uso, su reducido tamaño y la liviandad de las cámaras y es económicamente asequible. ${ }^{10}$

En su tesis "La video-animación: aplicaciones en los campos del desarrollo social y comunitario, la educación artística y el arte terapia", Ana Mampaso reflexiona sobre lo que ella entiende por video-arte terapia:

El factor de subjetividad en el uso del vídeo es lo que distingue una sesión de video-arte terapia de otra forma de video-terapia, donde no hay ninguna intención artística. La primera experiencia de video-arte terapia, son las investigaciones llevadas a cabo por McNiff y Cook en los años 73-75. Para Ira Heilveil (1984) cuando las personas crean sus propias obras en vídeo reflejan la idiosincracia que define la concepción individual del artista acerca del mundo. ${ }^{11}$

También dice Ana Mampaso: "Lo más desconcertante del vídeo de creación es la gran diversidad de productos que genera." 12

Muestra así su concepción general en torno al trabajo en video-arte terapia:

El vídeo también puede ser utilizado como herramienta en manos de los y las arte terapeutas, ampliando las fuentes del arte terapia más allá de los mecanismos tradicionales del dibujo, la pintura y la escultura. Hay muchos caminos por los que se puede incorporar el vídeo, uno es la de animar a las personas a utilizar el vídeo para crear sus propias obras y de ese modo, capitalizar su potencial para crear un sentimiento de autovaloración y crear expresión espontánea y catarsis. ${ }^{13}$

Parece por tanto el momento del encuentro de la videoarteterapia con el proceso vivido en las sesiones, pararse a observar cómo es esa relación que se establece con la cámara, con la imagen obtenida, con el montaje de lo producido, dónde se sitúa la cámara, qué se graba con ella o dónde se encuentra la materialidad de un medio que, según la hipótesis planteada, se hace físico en el momento

\footnotetext{
${ }^{10}$ MAMPASO, A. (2004) Video-arte terapia y educación. Artículo publicado en: Arteterapia y educación. Coord. Martínez Díez, N. y López Fdez. Cao, M., Comunidad de Madrid, Consejería de Educación.

${ }^{11}$ (Mampaso, 2004, p.29)

${ }^{12}$ (Ibidem. p.30.)

${ }^{13}$ (Ibidem. p.30)
} 
en que el lenguaje audiovisual transforma la mirada (o establece nuevos matices en la mirada) de la persona que acude a las sesiones.

\section{SOBRE MI PROPIA EXPERIENCIA CON VÍDEO EN ARTETERAPIA}

Hace tres años llevé a cabo un trabajo práctico ligado a la investigación en un máster de audiovisuales acerca del vídeo y su relación con la parálisis cerebral. Comenzó así la realización de una serie de vídeos, destinados a ser emitidos por televisión, en los que cada una de las personas con parálisis cerebral que colaboraban (cada capítulo tenía como protagonista a una persona diferente) mostraba al público algún aspecto de su vida cotidiana. Aquel acercamiento a la relación entre vídeo y discapacidad física fue claramente determinante: por un lado se me presentaba la dificultad del trabajo técnico, cada persona tiene muy diferentes capacidades y formas de expresión, lo que supone un reto a la hora de afrontar cada vídeo (con cada uno de ellos tuve que empezar de cero a la hora de encontrar un lugar para la cámara, realizar o controlar determinados movimientos, coger la cámara y comenzar a grabar, tomar decisiones), por otro lado esta experiencia abría una nueva vía de investigación: ¿me interesaba que el fruto de aquel trabajo sirviera como un acercamiento de la parálisis cerebral al gran público o lo que quería realmente era trabajar con la persona? ¿y esa otra persona? ¿qué buscaba al hacer esos vídeos? ¿qué le aportaban?

Con todo esto en mente comencé el Máster en Arteterapia y mis prácticas de $2^{\mathrm{a}}$ curso. De nuevo el vídeo y la parálisis cerebral estaban presentes, pero de una forma bien distinta: no trabajábamos en proyecto sino en proceso.

Mi falta de confianza en las posibilidades del vídeo al comienzo de las sesiones de arteterapia hacía que otras artes, como la escritura, fueran ganando terreno en el diálogo creativo con los realizantes. No estaba siendo capaz de darle el valor justo.

Poco a poco fui dejando que la cámara se colara en mis propuestas, que jugara con la movilidad del cuerpo de cada realizante, que las imágenes grabadas comenzaran a destilar nuevas y vibrantes historias desde su aparente cotidianidad, que lo captado consiguiera trasladarlos junto a su imaginario, a un nuevo espacio de creación.

Es por ello que el tema que rescato de las sesiones de videoarteterapia realizadas hasta el momento es el del uso de la cámara de vídeo y los medios audiovisuales para el acompañamiento en arteterapia, con la intención de relacionarlo con aquello que ha servido para comprender que las posibilidades que nos puede dar la imagen grabada en vídeo y el propio acto de grabar son inmensas y extrapolables, a partir de lo que se concluya en esta reflexión, al trabajo con cualquier grupo o persona en el terreno arteterapéutico. 


\section{UN TRABAJO EN PROCESO Y MULTIDISCIPLINAR: GRABAR, EDITAR, VISIONAR, PROYECTAR}

En la actualidad la tecnología vídeo resulta cercana, es esa facilidad para utilizar el medio lo que lo ha puesto a nuestro alcance, somos una sociedad invadida por la imagen, por las representaciones de la realidad. Muestra el tiempo y el movimiento, ilustra las situaciones. Resulta difícil, por tanto, vivir ajeno a su existencia. Nuestra vida siempre ha ido de la mano de la imagen en movimiento. La televisión, los vídeos infantiles, la primera vídeo cámara de la familia, el cine, el ordenador, youtube...

Todos hemos tenido alguna vez una cámara de vídeo en nuestras manos.

Está incorporada la opción de grabación en cualquier cámara de fotos e incluso se puede encontrar en los móviles más modestos. Todos podemos trabajar las imágenes, editarlas y jugar a ser montadores sin contar con demasiado presupuesto. La imagen obtenida parece realista, ilustrativa, pero eso puede resultar muy engañoso, ya que contiene mucho material subjetivo susceptible de ser analizado: qué se graba, cómo se graba, quién graba y en qué circunstancias, cómo coge la cámara, cómo se seleccionan y editan las imágenes...

Podemos comenzar este recorrido introductorio por el lenguaje audiovisual y su presencia en las sesiones de arteterapia destacando sus principales peculiaridades, que lo presentan como un arte con un potencial enorme, características que hacen al vídeo adquirir una entidad propia en su uso en las sesiones (alejándose de la plástica, la música, la escritura, la danza o el teatro y a su vez bebiendo de todas ellas):

-La materia es virtual.

-El tiempo: se introduce el factor de duración y velocidad en la producción.

-La introducción del sonido: permite repetir, alterar... El sonido debe compartir protagonismo con la imagen. El ritmo del discurso puede variar a medida que los sonidos se van combinando, se van sucediendo, van estableciendo nuevas relaciones con las imágenes.

-La "distancia" que se genera al no existir "contacto" con la materia. Dificultad en muchas ocasiones para tener la sensación de autoría.

-Desarrollo del mundo simbólico a partir de la grabación.

-La mirada (permite analizar): la perspectiva, las imágenes creadas, el encuentro con las variables.

-El rol del realizante: el proceso de vídeo en sí mismo hace que la persona combine múltiples facetas, es quien tiene la idea original, es el productor, el guionista, el director de fotografía, el cámara, el sonidista, el decorador, el iluminador, el montador...

-El aura de lo creado. El concepto, introducido por Walter Benjamin, del "aura" de la obra de arte pone en cuestión los lenguajes audiovisuales en relación con la capacidad de la obra para ser reproducida y la imposibilidad, gracias a o por culpa de ello, de hallarse frente a una pieza "Única". 
-Permeabilidad para su combinación constante con el resto de artes: todo puede entrar en juego (drama, danza, plástica, música, voz, escritura). Podríamos decir que nos permite elaborar múltiples combinaciones de técnicas y de recursos.

Existen innumerables relaciones que se pueden establecer con otras artes en cualquier punto del proceso, ¿qué pasaría si bailo mientras grabo? ¿y si escribo y a partir de ahí grabo o escribo a partir de una grabación? ¿Qué pasa cuando grabo mi voz? ¿Y si el propio realizante actúa ante la cámara? ¿Y si me permito jugar con la imagen fija?

\section{LA CÁMARA EN LAS SESIONES}

La cámara de vídeo no tiene por qué ser simplemente un elemento pasivo en las sesiones de arteterapia, se puede convertir en un elemento activo.

La cámara tiene un ojo a través del que se mira y se graba lo que hay alrededor. Capta una realidad que acontece y nos la devuelve embotellada, encriptada, distanciada, renovada, mágica.

La reflexión a la que nos invita Marián López-Fernández desde su libro "Memoria, ausencia e identidad" se centra en este caso en el dibujo, pero guarda una íntima relación con lo que tratamos de desarrollar en este artículo:

Dibujar implica observar. Observar implica tiempo, detenerse y fijar nuestra atención sobre una parcela de esa realidad que hemos elegido. Realizamos complicadas operaciones mentales en un breve espacio temporal: seleccionamos, abstraemos, convertimos un mundo en tres dimensiones, en movimiento y en color en algo bidimensional, fijo y en muchas ocasiones monocolor. La realidad ya no está allí, está aquí. El resultado no es la realidad, es nuestra experiencia sobre el hecho de contemplar la realidad. Una realidad que se transforma en acontecimiento propio a través de nuestro cuerpo: de nuestra percepción, de nuestro sistema cognitivo capaz de seleccionar, abstraer y sintetizar, y que comprende de repente, por ejemplo, cómo crece una hoja, sus complejas o aparentemente sencillas simetrías, las relaciones de proporción entre el objeto que dibujamos y su entorno, y de éste con nosotros mismos. ${ }^{14}$

¿Qué pasaría si todos los días grabaras la misma escena? (aunque sea en condiciones similares de luz y con la misma cámara) ¿La harías siempre igual? ¿Qué pasa si todos los días ves la misma escena? ¿Las sensaciones y el resultado serían los mismos?

Un pequeño gesto, un estado de ánimo, un pequeño temblor ya lo cambia todo.

A la hora de coger la cámara y grabar hay muchos elementos que nos darán pistas de los recursos utilizados por el realizante (para poder así percibir los detalles que nos ayudan a tirar del hilo, y así poder introducir pequeños cambios

${ }^{14}$ (López-Fernández Cao, 2011. p. 19) 
en las propuestas que permitan huir de las repeticiones y los clichés que se puedan encontrar asociados a la imagen vídeo para comenzar a crear un universo propio rico en elementos que posibiliten la evolución de la forma primera).

Algunos de los muchos factores a tener en cuenta y que determinan las cualidades de la grabación son el manejo de la cámara, sus reglas, el punto de partida, la técnica empleada, el espacio, el tiempo, la luz, la perspectiva de la cámara, el encuadre, la altura, el movimiento y la movilidad del realizante...

Una de las particularidades que se pueden encontrar en la grabación es la de que la cámara no puede ser utilizada por todo el mundo de la misma manera. Los útiles de grabación han de ser adaptados a la persona con la que se trabaja.

La cámara está hecha para diestros $\mathrm{y}$, aunque es ligera y parece fácilmente manejable, requiere de personas con total dominio de su cuerpo, que no tiemblen ni cojeen, que sean capaces de sostenerse por sí mismas (estas características están enfocadas a lo que se entiende como "buen uso" de la cámara de vídeo, la "perfección en el manejo" que nos hace creer que no existe un ser humano tras la cámara y que por tanto nos lleva al engaño de la objetividad).

$\mathrm{Al}$ ser las capacidades de cada realizante que nos encontramos tan diversas no es posible encontrar una fórmula precisa que permita el fácil manejo del dispositivo.

Cuerpo y máquina, como una extensión o prótesis, se han de fundir para conseguir que la cámara no sea un enemigo molesto sino un nuevo ojo desde el que percibir y captar la realidad. Hay que hacer de la cámara una cómplice y de lo grabado con ella un territorio nuevo por descubrir. Es por ello que el uso de la mano para coger la cámara es solo una opción más, ya que la ubicación de la cámara cuenta con tantas posibilidades como la imaginación del realizante le permita.

El viaje de la cámara de vídeo por el cuerpo, su cambio de ubicación, enriquecen el acto de grabar y confieren a la imagen resultante nuevas características que permiten a la persona encontrarse con una nueva realidad con la que ponerse a trabajar.

Por todo ello el trabajo con el vídeo como lenguaje artístico en las sesiones propone un recorrido artístico que enmarca de por sí el proceso arteterapéutico y posibilita la introducción de un cambio en la mirada invitándonos a reflexionar sobre la perspectiva con la que se ven las cosas y el inesperado encuentro con la realidad modificada.

Ya comienza, desde el propio acto de grabación, a ponerse en juego la importancia de la mirada y el interés que tiene estar atentos a su evolución.

\section{LA MATERIA INTANGIBLE: CARACTERÍSTICAS DE LA IMAGEN/VÍDEO Y EL AUDIO/VÍDEO}

En un viaje tomo imágenes, notas, compro recuerdos, cuento lo que ha pasado. Aunque viajemos acompañados esa experiencia será completamente diferente ya que cada uno registra la realidad vivida desde su subjetividad. 
Los recuerdos de viaje, lo que escribo, lo que fotografío, puede ir transformando la idea que tengo sobre la experiencia vivida en la medida en que diferentes factores cambian mi mirada hacia eso que he vivido, realizado, captado.

La persona nunca es un simple observador objetivo. Somos sujetos y, como tal, subjetivos. Las decisiones pueden ser azarosas o milimétricamente planificadas pero nunca carentes de subjetividad, de valores íntimamente ligados con lo humano.

Algunas de las características de la imagen/vídeo son la luz, el espacio, el enfoque, la cercanía a lo grabado, el factor tiempo, la velocidad, el encuadre, lo que se repite, lo que aparece en la escena y lo que se excluye, el tono, el brillo, el contraste...

Si nos centramos en el sonido podemos pensar en su intensidad, su vibración, la intencionalidad a la hora de captarlo, su contraposición a la imagen, la importancia que tiene para el conjunto, su fuerza expresiva, su procedencia (voces, sonidos de objetos, de la naturaleza...)...

Es importante tener en cuenta también el lugar donde se reproduce la imagen: visor de la cámara, televisión, pantalla de cine, ordenador, pared, sala (abarcándolo todo...)

Todo ello interviene en el proceso de creación audiovisual.

Pero dentro de ese poder que tienen las imágenes algo nos lleva a pensar que no serían nada sin la mirada que les devolvemos.

Una mirada amplificada, que no busca lo mismo a cada paso, que se detiene y selecciona, que intuye elementos que antes no vio, que introduce nuevas posibilidades a un discurso de corte audiovisual.

\section{LA CONSTRUCCIÓN DEL UNIVERSO SIMBÓLICO EN EL LENGUAJE AUDIOVISUAL: LA EDICIÓN}

Tras grabar y visualizar lo grabado comienza la reelaboración, a través de medios técnicos, del material creado. Esos medios técnicos son habitualmente el ordenador y los programas de edición (Final Cut, Adobe Premiere, Pinnacle Studio, Windows Movie Maker).

Hay muchos elementos que se ponen en juego ya que la edición permite el encuentro con el error (aquello que se suprime), con lo que no es como se había esperado, la introducción de banda sonora (extras sonoros añadidos, voces...) y elementos de transición, la incorporación de filtros y elementos visuales (luminosidad, velocidad, realizar nuevos encuadres, cambios de tono y color, prescindir de alguna parte, incluir escritos...), la existencia del tiempo, la alteración del ritmo y la duración.

Es posible trabajar desde distintos tipos de montaje: narrativo o clásico (se basa en crear una historia, elaborar un guión, trabajar de la mano con la escritura, conformar la estructura narrativa de la producción audiovisual), expresivo (determina el ritmo de la acción), ideológico (utiliza las emociones) o creativo (no 
tiene necesariamente una ordenación cronológica, sino que toma los recursos del vídeo para conformar una operación totalmente nueva).

Para adentrarse en el universo simbólico creado a partir del lenguaje audiovisual es posible elaborar un discurso de análisis de la imagen a partir de métodos retóricos de otras disciplinas lingüísticas. Tomando expresiones gramaticales se puede hablar de la construcción de las imágenes a través de unas normas. La morfología estudia la composición de las imágenes. Por medio de la sintaxis aplicada al lenguaje audiovisual podemos analizar la disposición y estructura del contenido de las imágenes. La semiótica nos puede aportar nuevos recursos para explorar la arbitrariedad lingüística de las imágenes. Sin olvidar por supuesto la poética, que se centra en la creatividad de las imágenes.

Algunos ejemplos de figuras retóricas a tener en cuenta para comprender el universo simbólico que se crea:

De alteración: ambigüedades, personificaciones, caricaturizaciones, animalizaciones, transcodificadores: alteración en el sentido de la expresión, anacronías temporales, ilusiones ópticas, alteración del orden de las secuencias (montajes alternos, montajes paralelos, montajes invertidos, montajes ideológicos, de atracciones, montajes rítmicos).

De sustitución y permutación: alusiones, comparaciones evidentes entre dos o más imágenes y objetos, metáforas, alegorías, metonimias: relaciones por causalidad, procedencia, sucesión, dependencia, antonomasias: designación de algo individual por algo común, ironías, símbolos, paradojas.

De supresión: elipsis, encabalgamientos, alusión a lo que está fuera de campo, supresión parcial (imagen partida que continúa fuera de cuadro), sinécdoque (mostrar una parte por el todo), reducción del discurso audiovisual, resumen, interrupciones y cortes, silencios, supresiones.

Por adición: acumulación de citas, condensación de imágenes, repeticiones, amplificaciones, enumeraciones, gradaciones progresivas ascendentes o descendentes de objetos, exageraciones, alabanzas, insistencias, derivaciones de una misma estructura visual o discurso, reduplicaciones, semejanzas y rimas visuales.

Durante la edición y el montaje la imagen adquiere nuevas características ya que podemos jugar con lo grabado, desordenarlo, hacer que vaya más rápido o más lento, incorporar fundidos y efectos, cambiar el tono, la luz, el encuadre, tomar fotogramas... Gracias a este nuevo paso en el proceso podemos sumar elementos que posibilitan el enriquecimiento de lo creado, pero que, a su vez, nos permiten volver a la imagen primera y contrastarlo, ya que aunque alteremos las imágenes éstas pueden seguir conservándose "intactas" si vamos guardando diferentes archivos de cada paso del proceso de edición.

Por ello planteo que la materia no se transforma "físicamente", el que se transforma es el realizante, cambia su mirada hacia la producción, se encuentra con nuevas realidades modificadas o con la misma imagen vista desde una nueva perspectiva. 


\section{ANÁLISIS FORMAL DE LA PRODUCCIÓN}

El discurso generado arranca en el momento en que la propuesta se lanza o se enlaza con la propuesta anterior y comprende todos los instantes relacionados con la creación: la búsqueda de posibilidades, el encuentro con aquello que se quiere grabar, la grabación, el visionado y la selección de lo grabado, la edición de las imágenes (no necesariamente todo ello se da en cada proceso terapéutico).

Los puntos que paso a redactar a continuación podrían ser los parámetros a través de los que analizar formalmente la manera de grabar, el material audiovisual surgido y la trasformación de ese lenguaje audiovisual.

1. La acción de grabar.

- La propuesta o punto de partida.

- Selección de la cámara.

- Tipo (Analógica, digital). Tamaño. Peso. Calidad. Sensibilidad.

- Características: tipo de objetivo, en color, con cinta/tarjeta de memoria.

- Ubicación: en el cuerpo, desde otro lugar (trípode, suelo, silla...)

- Selección de dónde, cómo, cuándo, qué.

- Espacio: lugar, fuera/dentro.

- Luz: día/noche, sol/nubes.

- Qué sale/qué no sale en plano.

2. El lenguaje audiovisual (aquello que se ha tomado con la cámara, "en bruto"). Parámetros compositivos.

- Tamaño: rectángulo, circular, díptico, tríptico.

- Escala: formato, cánones establecidos. La cercanía a lo grabado, encuadre (¿corta los objetos?).

- Forma: proporción, desproporción, sombras, siluetas.

- Contenido: descripción de figuras, fondos.

- -Espacios: abiertos o cerrados, vacíos o poblados, partes o conjuntos, delimitaciones, entidades independientes o complementarias, reales, ficticios, soñados o imaginados, virtuales, simbólicos, imposibles, definidos (abstractos o concretos), naturaleza (interiores, exteriores), calificación (abiertos, cerrados), poblados (habitados, amueblados), despoblados: vacíos, espacios íntimos, personales, grupales.

- Color: fríos, cálidos, predominios, escala tonal, si es blanco y negro, grados de definición.

- Composición: predominio de la narrativa o descripción, cuántas historias aparecen, si son figuras regulares o irregulares, cómo son...

- Ángulos: cómo se orienta la cámara.

- Volumen: bidimensionalidad, tridimensionalidad, perspectiva, profundidad de campo.

- Movimientos acelerados, ralentizados, parada de imagen.

- Textura: gradiente textual, nitidez, grados de abstracción

- Ritmo: tensión-estatismo, equilibrio-desequilibrio. 
- La temporalidad. Cuándo se decide cortar.

- Líneas de lectura: peso visual, si hay una o varias líneas de lectura, puntos de atención.

- Variaciones en la manera de hacer, los objetos recogidos y la manera de captarlos (varía o por el contrario se repite de forma insistente el modus operandi.)

- Cómo se recogen los sonidos (preocupación por el contexto sonoro).

- Juegos ópticos: espejos, reflejos, anamorfosis, deformaciones.

3. Proceso de Selección-Transformación-Montaje de Imagen y Audio.

- Lo que se toma (lo que gusta y lo que no).

- Lo que no es como se había esperado (¿volver a grabar?)

- Elementos que interfieren/enriquecen: El encuentro con la imagen/audio modificados.

- La banda sonora (extras sonoros añadidos, voces...)

- Los elementos de transición: por corte, por fundido, encadenado a otras imágenes, a negro, a un color específico, por diversas sobreimpresiones, por sonido, por cierres y aberturas de caché o iris, por cortinillas (laterales, verticales, transversales), por barrido, por desenfoque a enfoques, por efectos especiales.

- Los filtros, elementos visuales: luminosidad, velocidad, ajustar el encuadre (recorte, rotación, ampliación), tono y color, prescindir de alguna parte, incluir escritos, distorsión del ritmo del montaje, alteración de la imagen (cambios en la perspectiva, suavizado, saturación, corrección del color, distorsión...)

- La estructura narrativa de la producción audiovisual. Crear una historia: el guión, la relación con la escritura.

- El Tiempo, la duración, la velocidad.

A partir de esta concepción del universo simbólico es posible ir tejiendo el hilo de las sesiones a través de los cambios que se van produciendo en la mirada. El videoarteterapeuta ha de permanecer atento a la forma en que la persona capta, recoge, selecciona, edita y altera los elementos que surgen en cualquier punto del proceso audiovisual y desde ahí obtener pistas para su intervención.

\section{EVOLUCIÓN EN LA PRODUCCIÓN: EL CAMBIO EN LA MIRADA}

La mirada es fundamental en el proceso. El acompañamiento se va elaborando al percibir cómo el realizante va cambiando la manera de mirar su producción.

Intentemos aproximarnos a cómo el proceso audiovisual descrito en los capítulos anteriores encuentra su "materialidad" en el cambio en la mirada.

¿Qué entendemos como ver/percibir? ¿En qué se diferencia de la mirada?

Ver, percibir, es sensorial, es un acto único en cada uno de nosotros.

Mirar es escoger, descartar, posicionarse, elegir, decidir, cambiar, vagar, adentrarse en lo que se desea. 
El proceso de creación en vídeo implica un cambio/evolución en la mirada.

Dediquemos un primer instante a reflexionar sobre la manera de percibir.

En este camino de la percepción, aquello que falta (los sentidos que no están representados) lo completo yo. La imagen y el sonido captados con la cámara y posteriormente reproducidos me pueden remitir al olor, al sabor o al tacto de aquello que veo y escucho a través de la pantalla según yo lo tengo en mi recuerdo. El vídeo es eminentemente visual y auditivo y por ello abre la puerta de la imaginación del autor que trata de completar la información recibida a partir de la imagen y el sonido que se crean. Los matices a los elementos nos los proporciona nuestro conocimiento, nuestro recuerdo, los completamos y enriquecemos.

Por tanto, esta revisión por el camino de la visión nos remite no necesariamente a la percepción visual sino más bien a un "ver con todo el cuerpo".

El libro de Julio Romero, "El arte como transformación: Mirar con otros ojos. Propuesta didáctica" se inscribe dentro de una colección de diferentes experiencias didácticas propuestas por profesores universitarios, basándose en la obra de algún artista para realizar una intervención en el ámbito escolar. En este caso se aproxima a la obra de Paloma Navares, una artista visual con amplio recorrido que centra su trabajo en el cuerpo y los modos de ver, además de otros muchos aspectos. Destaca en su trabajo su propia experiencia con lo visual ya que desde niña padece una enfermedad degenerativa que altera su visión, de la que ella misma se sirve para nutrir sus creaciones. La propuesta didáctica:

Se trata de hacer presente en educación esa máxima creativa de "hacer familiar lo extraño y hacer extraño lo familiar". Queremos "Mirar con otros ojos", poner en práctica diferentes modos de ver, diferentes perspectivas para mirar lo que nos rodea y a nosotros mismos. ${ }^{15}$

Todo el cuerpo se encuentra presente a la hora de percibir. La percepción es la manera de interiorizar, de comprender lo que se ha hecho y lo que se está haciendo.

Existe un mundo subjetivo que cada uno de nosotros nos hemos creado.

Cada persona percibe un espectro de la realidad muy limitado y, a partir de él, se crea su mapa del mundo. Mientras vamos dibujando este mapa de nuestra realidad, muchos filtros nos impiden que la información llegue completa.

El principal de esos filtros lo representan los sentidos, nuestra ventana al mundo. Imaginemos cómo podría ser la percepción del mundo para alguien ciego, o sordo, o que pase toda su vida en una silla de ruedas. El dibujo de ese mapa cambiará por completo.

Es conveniente dedicar un tiempo al análisis de las muchas posibilidades que existen de acercarse a la realidad.

Cuando hablamos de percepción y pensamiento existen diferentes posibilidades de recibir la información que nos llega del exterior. Puede haber personas que se centren más en lo visual o en lo auditivo o quizá en aquella información que

${ }^{15}$ (Romero, 2009, p. 6) 
llega por el resto de sentidos. Los estímulos siempre se nos presentan de manera desestructurada y cada uno de nosotros, aunque saquemos un poco de partido a cada una de esas percepciones, desarrollamos una como prioritaria para procesar la información.

Otro de nuestros filtros de la realidad nos lo da el lenguaje. Cuando le pones nombre a algo, comienza a existir. No se suelen tener en cuenta los matices que engloba un término genérico, como por ejemplo la cantidad de colores que encierra un prado, mientras nos limitemos y lo denominemos simplemente verde.

La cuestión es que, llegue por donde llegue, la información entra en nuestro cerebro de manera no lineal y es al contarla o escribirla como le vamos dando forma y la convertimos en una secuencia ordenada.

La persona se encuentra, a partir del uso del lenguaje audiovisual, ante una realidad que se muestra a través del filtro de la cámara. Y esta manera de percibir, única en cada sujeto, va transformando la producción, dejando que cada detalle sea partícipe, que se puedan elaborar, a partir de todo aquello que llama la atención del realizante, nuevas maneras de enfrentarse a las imágenes que surgen de su entorno a través del filtro de la cámara, de la posición adoptada al grabar, de aquello que se selecciona y lo que se deja pasar, de las capacidades del realizante, de su estado de ánimo...

Pero hay una característica que se ha de sumar a lo ya mencionado, y esa es la mirada. La mirada entendida como acto pulsional. Hay algo del deseo que empuja a fijar la atención de una nueva manera en los lugares, los objetos, las personas.

Afinar la mirada, darle un sentido, viajar por ella a territorios desconocidos, nos enriquece.

\section{LA MIRADA}

Jonh Berger dedica su libro "Mirar" a Anthony Barnett ya que, según explica el autor, "está siempre mirando"16. En el libro el ojo de la cámara y el ojo del artista nos hablan del significado oculto en la mirada cotidiana con la que contemplamos paisajes, animales o personas queridas.

Ángel Román reflexiona desde su libro "Ensayos de la mirada" sobre tres tipos de modos de mirar que él ejemplifica con grandes historias cinematográficas. Divide su libro en tres capítulos: "Miradas lejanas", "Miradas íntimas" y "Miradas extrañas". Inés Praga Terente destaca en el prólogo de la obra: "Siempre he pensado que la mirada no es un don sino una conquista. Se consigue mirar después de muchos años de ver, de contemplar, de descifrar realidades y de interpretar mensajes ${ }^{, 17}$

\footnotetext{
${ }^{16}$ (Berger, 2001, p. 2)

${ }^{17}$ (Román, 2004. p. 13.)
} 
El proceso vivido en la mirada, el viaje que nos hace experimentar, es un camino que nadie te obliga a recorrer y que tú mismo decides de qué manera llevarlo a cabo.

Nacemos con la capacidad de ver, de percibir con los sentidos, de ser partícipes de aquello que ocurre a nuestro alrededor a través de imágenes.

Pero mirar se encuentra en otro lugar, mirar implica establecer nuevas relaciones con lo que nos rodea.

En algunos idiomas, este es el caso del francés, una misma palabra sirve para hablar de mirada y visión, "le regard". Explica Rosa Askenchuk en su artículo "Esquicia de la mirada y pulsión escópica en Lacan" que:

El término francés "le regard" sirve para ambas, pero los traductores de Jacques Lacan utilizan "mirada", mientras que los de Jean-Paul Sartre usan "visión". En el pensamiento de Sartre, "le regard" (la visión) está del lado del sujeto, en tanto que en los desarrollos más avanzados de Lacan "le regard" (la mirada) está del lado del objeto, en el campo del Otro ${ }^{18}$

Avanzando en la lectura del artículo descubrimos cómo trata más en profundidad los intentos de diferentes autores por acercarse a la mirada definida por Lacan:

Se llegó a la decisiva conclusión de que no es lo mismo concebir la pantalla como un espejo (concepción derivada del estadio del espejo de Lacan) o el espejo como una pantalla (concepción que debería derivarse de una correcta comprensión de la mirada lacaniana) ${ }^{19}$

Esta nueva manera de entender la mirada aporta un nuevo enfoque, ya que el lugar donde se proyecta el vídeo ya no es entendido como un mero espejo donde se refleja el narcisismo del sujeto, sino que "se vuelve una pantalla, un elemento otro, opaco, que alcanza y suscita la mirada del sujeto.

$\mathrm{Y}$, a partir de reflexionar acerca de los escritos de Lacan en torno a la mirada, concluye que:

El ojo no es meramente un órgano de la percepción, sino también un órgano de placer. Hay una dialéctica del ojo y la mirada - «el ojo» como capturado en el orden simbólico y «la mirada» como buscando la satisfacción de una fantasía narcisista - puesto que todos los objetos, sujetos a la pulsión escópica, participan en el conflicto entre la fantasía imaginaria y las exigencias de lo simbólico, el deseo del Otro. El sujeto hablante nunca puede quedar completamente atrapado en lo imaginario (...). No puede suponerse que el proceso que produce la operación ideológica de constitución del sujeto trabaje sin error. ${ }^{21}$

Si nos dirigimos a lo que el propio Lacan escribió sobre la mirada:

\footnotetext{
${ }^{18}$ Aksenchuk, Rosa: "Esquicia de la mirada y pulsión escópica en Lacan”. Publicado en: http://www.observacionesfilosoficas.net/ezquiziadelamirada.html [09/12/2013]

${ }^{19}$ (Íbidem p.1)

20 (Íbidem p.1)

21 (Íbidem p.1)
} 
La mirada no se nos presenta más que bajo la forma de una extraña contingencia simbólica de lo que encontramos en el horizonte y como tope; a saber, la carencia constitutiva de la angustia de la castración. El ojo y la mirada, tal es para nosotros la esquizia en la que se manifiesta la pulsión al nivel del campo escópico. En nuestra relación con las cosas tal como es constituida por la vía de la visión y ordenada en las figuras de la representación, algo se transmite de piso en piso para estar siempre en ella en algún grado elidido -eso es lo que se llama la mirada. $^{22}$

\section{LA MIRADA Y EL LENGUAJE AUDIOVISUAL}

La materialidad existe en el hacer videográfico mientras exista una mirada que sea capaz de sorprenderse con los hallazgos y abrirse al cambio.

Comentaba en la introducción que el vídeo no solo se limita a proporcionar una imagen de la realidad, es una escena condicionada por la mirada de la persona que la graba, la que la edita y la que la observa (que en este caso es la misma). Y, por supuesto, de aquello que se está grabando.

Aquí reside uno de los puntos de mayor interés para el uso terapéutico.

¿Qué ocurre cuando el espectador y el autor son la misma persona, cuando la producción se hace para uno mismo?

¿Hacia dónde se dirige esa mirada? ¿Desde dónde nos situamos para crear una imagen? ¿Cómo puede cambiar nuestra manera de mirar lo realizado?

Cuando la mirada se encuentra con un nuevo lenguaje, el audiovisual, se crean nuevos encuentros entre aquello que es mirado y la persona que mira.

La mirada viaja desde lo conocido, lo habitual, hacia nuevos territorios donde es la protagonista.

Porque ahí se encuentra la clave, en el acercamiento a la producción en vídeo en arteterapia, en el cambio en la mirada. En el cambio de dirección, de intención, de recorrido, de intensidad, algo mueve a esa mirada y le hace variar su "modo de hacer". Un estado de ánimo, un nuevo conocimiento, una variación introducida por un tercero (como puede ser el arteterapeuta), un encuentro con algo que había pasado inadvertido...

Y desde ese momento todo va cambiando, la manera de coger la cámara, de disponerse a grabar, de seleccionar un encuadre, la manera en que se mira y edita lo grabado. Y de esa forma también adquiere un nuevo matiz la manera en que se dirige la mirada hacia aquello que ocurre cuando el lenguaje audiovisual deja de ser el intermediario.

${ }^{22}$ (Lacan, 1990) 
El proceso que vive la mirada, la manera de acercarse a la producción, de ver, organizar y captar aquello que se quiere grabar y de observar lo grabado vive muy diferentes etapas.

Ahí reside uno de los grandes pilares en los que el vídeo se sustenta y que le hacen adquirir su verdadera materialidad, su verdadero peso.

Es importante saber acompañar a la mirada en el proceso. Una mirada entendida no solo como "Modo de ver", modo de acercarse al entorno y a lo creado desde los sentidos, sino también, como ya hemos visto anteriormente, como motor pulsional desde el que retomar las relaciones existentes con el entorno y con la creación.

\section{LA MIRADA PRESENTE EN LA CONSTRUCCIÓN DEL UNIVERSO SIMBÓLICO}

La determinación que la mirada ejerce a nivel pulsional se puede tomar como motor de la producción audiovisual, ya que, si partimos de lo expuesto anteriormente podemos observar que existen detonadores psicológicos que determinan la construcción del universo de creación de cada individuo. De entre los contenidos que se presentan en la configuración de un discurso destacan los relacionados con las narrativas de lo inconsciente. A partir de ellos se puede definir la posición desde donde se narra un discurso, la determinación pulsional que se sitúa detrás de dicho discurso, el diseño de la estructura del universo imaginario e incluso las posibilidades de reinvención de dicho universo.

La mirada pulsional puede aparecer ligada a la producción, al registro imaginario, a la estructura visual. Es muy importante saber cómo cada realizante establece las bases para esa producción visual.

Cuando se ponen en relación el discurso inconsciente y la producción audiovisual es muy posible ir abriendo las puertas para poder modificar la composición del mismo, aportar herramientas que establezcan cambios en las narrativas relacionadas con el espacio donde el discurso toma lugar.

La aparición de estos mundos imaginarios a través de la cámara, la imagen y el montaje nos plantea la posibilidad de creación de nuevos discursos y/o universos, presentando una manera distinta de observar la realidad.

Puede que lo que vemos, las imágenes que día a día devoramos, eclipsen nuestra mirada. Pero esta mirada, aunque tapada, sigue siendo la que, desde la sombra, organiza nuestro universo de visión. Una mirada de la que muchas veces no somos conscientes pero que determina la escena que nos creamos del mundo.

\section{CONCLUSIONES}

Me gustaría comenzar destacando el acercamiento al lenguaje audiovisual realizado en este artículo, desgranando sus diferentes características, intentando 
detallar las claves para el análisis formal de la producción. Dicho lenguaje toma, gracias a sus peculiaridades, entidad propia como herramienta, no solo creadora sino también arteterapéutica. Además, el arte del vídeo, en su uso en arteterapia, aporta grandes posibilidades para el trabajo con cualquier tipo de persona o colectivo.

A través del análisis del proceso llevado a cabo con el vídeo como medio en arteterapia se puede apreciar como cada uno de los pasos del proceso videográfico juega un papel relevante en la evolución de la producción. Grabar, visionar, editar, proyectar y analizar la producción son algunas de las muchas acciones que la persona efectúa durante las sesiones de arteterapia.

Nos hemos encontrado a lo largo del desarrollo de este artículo con términos que han ido adquiriendo un significado en relación con la temática tratada como "realizante", "mirada" o "materialidad".

El realizante se aproxima a la creación audiovisual desde los sentidos, todo aquello que ocurre a su alrededor altera y enriquece lo realizado.

Sin embargo es la mirada la que confiere su materialidad al universo de creación, ya que es el deseo, el encuentro con la producción y el desarrollo de ambas (mirada y producción) lo que determina el proceso arteterapéutico.

Ver no es lo mismo que mirar, el cambio en los modos de ver tiene una gran importancia porque nos ayuda a descubrir nuevas posibilidades de creación y a sorprendernos con aquello que está a nuestro alrededor, sin embargo la evolución en la mirada se localiza en el deseo del sujeto, en su intención, en aquello que lo mueve, de ahí que la materia audiovisual adquiera su verdadero sentido a partir de la mirada devuelta por su realizador.

Por ello es necesario continuar el camino abierto y profundizar más en el complejo territorio de la mirada ya que ha sido posible observar a través de esta reflexión el interés que suscita el término cuando se pone en relación con el material audiovisual, ya que permite aproximarse de una manera más afinada al mundo del acompañamiento en videoarteterapia y al territorio por el que transita la producción de cada sujeto.

\section{REFERENCIAS BIBLIOGRÁFICAS}

BERGER, J. (2001). Mirar. Barcelona, Ed. GG.

KLEIN, J.P. (2006). Arteterapia. Una introducción. Barcelona, Octaedro.

LACAN, J. (1990). Los cuatro conceptos fundamentales. Seminario XI. Barcelona, Ed. Paidós.

LÓPEZ-FERNÁNDEZ CAO, M. (2011). Memoria, ausencia e identidad. El arte como terapia. Madrid, Eneida. 
LÓPEZ MARTÍNEZ, M. D. (2009). La Intervención Arteterapéutica y su Metodología en el Contexto Profesional Español. Tesis Universidad de Murcia. Dirigida por: Dra. Ma Gracia Ruiz Llamas y Dr. Alfredo Cuervo Pando.

MAMPASO, A. (2004). La video-animación: aplicaciones en los campos del desarrollo social y comunitario, la educación artística y el arte terapia. Tesis Universidad Complutense de Madrid.

ROMÁN, Á. (2004). Ensayos de la mirada. Madrid, Estudio Eurolaser.

ROMERO, J. (2009). El arte como transformación: Mirar con otros ojos. Propuesta didáctica. Madrid, Eneida.

SONTAG, S. (2008). Reborn: Journals and notebooks 1947-1963. New York, Farrar Straus \& Giroux.

VVAA (2008). Arteterapia. La creación como proceso de transformación. Barcelona, Octaedro. 